OPEN ACCESS

Edited by:

Paolo Miccoli,

University of Pisa, Italy

Reviewed by:

Clara Ugolini,

University of Pisa, Italy

Sara Ahmadi,

Brigham and Women's Hospital and Harvard Medical School, United States

${ }^{*}$ Correspondence:

Guixing Li

liguixing27@163.com

Specialty section: This article was submitted to

Thyroid Endocrinology,

a section of the journal

Frontiers in Endocrinology

Received: 11 September 2021

Accepted: 22 November 2021

Published: 15 December 2021

Citation:

Liu Q, Yin M and Li G (2021) Antithyroglobulin Antibody Variation

During Follow-Up Has a Good Prognostic Value for Preoperative Antithyroglobulin Antibody-Positive

Differentiated Thyroid Cancer Patients: A Retrospective

Study in Southwest China.

Front. Endocrinol. 12:774275. doi: 10.3389/fendo.2021.774275

\section{Antithyroglobulin Antibody Variation During Follow-Up Has a Good Prognostic Value for Preoperative Antithyroglobulin Antibody-Positive Differentiated Thyroid Cancer Patients: A Retrospective Study in Southwest China}

Qianhui Liu, Mengting Yin and Guixing $L i^{*}$

Department of Laboratory Medicine, West China Hospital of Sichuan University, Chengdu, China

Objective: Antithyroglobulin antibody (TgAb) is a potential tumour marker for detecting differentiated thyroid cancer (DTC) recurrence, but insufficient data have supported its clinical applications. Our study aimed to describe the changing trend of TgAb after surgery and identify the relationship between this trend and clinical outcomes.

Patients and Methods: We reviewed the electronic records of 1,686 DTC patients who had undergone total thyroidectomy $(T T)$ and radioactive iodine $\left({ }^{131} \mathrm{I}\right)$ therapy at West China Hospital of Sichuan University from January 2015 to December 2017. Finally, 289 preoperative TgAb-positive DTC patients were included and divided into four subgroups depending on the clinical outcome: Group A (tumour free), Group B (uncertain), Group C (incomplete biochemical response), and Group D (structural disease). The patient demographics, tumour characteristics, operations, pathology reports, and all serological biomarkers were reviewed and compared, and the prognostic efficacy of TgAb was evaluated.

Results: Among all 1,686 patients, 393 (23.65\%) were TgAb positive (>40 IU/ml) preoperatively. The TgAb level in Group A decreased significantly after surgery and ${ }^{131}$ I therapy and stabilised at a low level after $1-2$ years of ${ }^{131}$ I therapy. However, in the other three groups, the decrease in TgAb was not significant after treatment. Conversely, TgAb declined slowly and remained stable or increased. The variations in TgAb relative to the preoperative level of Group A were significantly larger than those of Groups B, C, and D at most time points of follow-up ( $p<0.001)$. By receiver operating characteristic $(R O C)$ analyses, the variations of $\mathrm{TgAb}>-77.9 \%$ at 6 months after ${ }^{131} \mathrm{I}$ therapy (area under the curve $(A \cup C)=0.862 ; p<0.001)$ and $\mathrm{TgAb}>-88.6 \%$ at 2 years after ${ }^{131} \mid$ therapy (AUC = $0.901 ; p<0.001$ ) had good prognostic efficacy in tumour-free survival. When the variation in TgAb $>-88.6 \%$ at 2 years after ${ }^{131}$ I therapy was incorporated as a variable in the 
American Thyroid Association (ATA) categories, both intermediate- and high-risk patients also had a significantly increased chance of being tumour free (from $75.68 \%$ to $93.88 \%$ and $42.0 \%$ to $82.61 \%$, respectively).

Conclusions: For preoperative TgAb-positive DTC patients, variations in TgAb $>-77.9 \%$ at 6 months after ${ }^{131}$ I therapy and $\mathrm{TgAb}>-88.6 \%$ at 2 years after ${ }^{131}$ I therapy had good prognostic efficacy. Their incorporation as variables in the ATA risk stratification system could more accurately predict disease-free survival.

Keywords: thyroid cancer, prognosis, antithyroglobulin, biomarker, DTC (differentiated thyroid cancer)

\section{INTRODUCTION}

Thyroid cancer is currently the fifth most common cancer diagnosis in women. By 2030, it is estimated to be the second leading cancer diagnosis in women and the ninth leading cancer diagnosis in men (1). Differentiated thyroid cancer (DTC) accounts for most thyroid cancers, mainly papillary thyroid cancer (PTC) and follicular thyroid cancer (FTC). The prognosis of DTC patients is good; however, instances of persistent or recurrent disease, such as local lymph node metastasis, are not uncommon; thus, long-term observation after the surgery of DTC patients is necessary. In the follow-up of DTC patients, thyroglobulin ( $\mathrm{Tg}$ ) is the most sensitive and specific tumour marker for the early detection of recurrence (2). However, antithyroglobulin antibody $(\mathrm{TgAb})$ shows potential interference with the Tg assay, particularly the immunometric assay (IMA), by forming the $\mathrm{Tg}-\mathrm{TgAb}$ complex, compromising the clinical usefulness of monitoring Tg in DTC patients for recurrence (3, 4). Thus, simultaneous measurement of TgAb is essential (5).

In the follow-up of DTC, the greatest challenge is patients with serum Tg-IMA concentrations suggesting tumour absence in whom it is not possible to ensure whether this finding indicates complete remission or underestimated $\mathrm{Tg}$ due to the interference of TgAb (6). Many studies have focused on improving Tg detection technologies, such as liquid chromatography/tandem mass spectrometry and radioimmunoassay, but the former may cause false-negative results in many patients with structural disease (7-9); the latter is unsuitable for large-scale clinical applications and may cause false-positive results positives.

Currently, Tg measurement is widely performed using second-generation IMA in practical clinical work, and interference with detectable $\mathrm{TgAb}$ is inevitable. Currently, no optimal assay exists to detect Tg that can avoid interference from $\mathrm{TgAb}$. Theoretically, the body produces $\mathrm{TgAb}$ because of $\mathrm{Tg}$ expression; thus, $\mathrm{TgAb}$ concentrations should respond to changes in Tg-secreting thyroid tissue. For DTC patients who have undergone total thyroidectomy (TT) and ${ }^{131} \mathrm{I}$ therapy, no residual thyroid tissue should be detected in the body theoretically; ideally, TgAb should be undetectable. Therefore, we are justified in holding that the TgAb trend can be used as a more reliable tumour marker in the follow-up of DTC patients and can be a better predictor of persistent/recurrent disease.

Although some studies have focused on the relationship between TgAb and the clinical outcomes of DTC, the current literature does not provide sufficient data to provide evidencebased answers to many questions arising in the care of TgAbpositive DTC patients (10). The general conclusion is that a reduction $>50 \%$ in the $\mathrm{TgAb}$ concentration is associated with a low risk of persistent/recurrent disease $(11,12)$. However, a $50 \%$ $\mathrm{TgAb}$ decline was established empirically, not statistically. Our study calculated variations in $\mathrm{TgAb}$ at every follow-up time point for each subject, describing the long-term dynamic change trend of TgAb and finding the relationship between this trend and the clinical outcome.

\section{MATERIALS AND METHODS}

\section{Study Objectives}

This was a retrospective study approved by the Ethics Committee of West China Hospital of Sichuan University. We reviewed the electronic records of 1,686 DTC patients who had undergone TT and radioactive iodine $\left({ }^{131} \mathrm{I}\right)$ therapy at our hospital from January 2015 to December 2017. The patient demographics, tumour characteristics, operations, pathology reports, and all serological biomarkers were carefully reviewed. The tumours were grouped into stages according to the 8th Tumour-Node-Metastasis Classification of the American Joint Committee on Cancer, and the risk of recurrence category followed the 2015 American Thyroid Association (ATA) risk stratification system (2).

In this study, all operations were performed by three experienced thyroid surgeons who had more than 10 years of experience in thyroid operations in West China Hospital. All the patients had undergone TT, and neck lymph node dissections were performed according to preoperative imaging studies, the levels of serological indicators, and intraoperative morphological appearance. After surgery, all the study patients had received ablative ${ }^{131} \mathrm{I}$ therapy. Treatment dosing was determined empirically using 30 to $100 \mathrm{mCi}$ for thyroid remnant ablation and 100 to $200 \mathrm{mCi}$ for postoperative residual neck lymph node metastases.

\section{Follow-Up}

The thyroid-stimulating hormone (TSH), FT3, FT4, Tg, and TgAb levels were measured 1 month after surgery, before ablative ${ }^{131}$ I therapy, and 1 and 6 months after ablative ${ }^{131}$ I therapy. Next, the patients were followed up by annual measurements of the TSH, FT3, FT4, Tg, and TgAb levels and neck ultrasound. Other 
imaging methods, such as chest and mediastinal CT and fluorine-18 fluorodeoxyglucose-positron emission tomography (FDG-PET)/CT, were performed when the basal Tg level (with suppressed $\mathrm{T} 4$ and $\mathrm{TgAb}$ negativity) $>1 \mathrm{ng} / \mathrm{ml}$ or the TgAb level remained positive or was increasing. For patients with persistent/ recurrent disease, additional ${ }^{131} \mathrm{I}$ therapy and repeated surgery were performed at the discretion of the attending physician.

\section{Definitions of Clinical Outcomes}

All the clinical data, including imaging findings (neck ultrasound in all patients, diagnostic whole-body ${ }^{131} \mathrm{I}$ scintigraphy, and chest and mediastinal CT, and FDG-PET/CT in selected patients), the basal Tg levels, TgAb levels, fine-needle aspiration (FNA), and postoperative pathological reports, were used to define the clinical outcomes.

Patients were considered tumour free if they had suppressed $\mathrm{Tg}<1 \mathrm{ng} / \mathrm{ml}, \mathrm{TgAb}<40 \mathrm{IU} / \mathrm{ml}$, and no structural evidence of disease. Patients were considered to have persistent disease if they had suppressed $\mathrm{Tg} \geq 1 \mathrm{ng} / \mathrm{ml}$ or $\mathrm{TgAb} \geq 40 \mathrm{IU} / \mathrm{ml}$ with a continuous increase, any evidence of disease on imaging, or biopsy-proven disease (cytology or histology). Patients with persistent disease were further classified as having an incomplete biochemical response (suppressed $\mathrm{Tg}>1 \mathrm{ng} / \mathrm{ml}$ or $\mathrm{TgAb} \geq 40 \mathrm{IU} / \mathrm{ml}$ with a continuous increase without a structural correlate). Patients were considered to have structural disease if cytology/histology was positive or imaging findings were highly suspicious for metastatic disease. Patients with suppressed $\mathrm{Tg}<1$ $\mathrm{ng} / \mathrm{ml}, \mathrm{TgAb} \geq 40 \mathrm{IU} / \mathrm{ml}$, and stability during the entire followup were considered uncertain.

\section{Laboratory Analysis}

The high-sensitivity electrochemiluminescence immunoassay (Roche Diagnostics GmbH; cobas e 601 from 2015 to 2020 and cobas e 801 from 2020) was used to measure TSH (measuring range: $0.005-100 \mu \mathrm{IU} / \mathrm{ml})$, FT3 (0.6-50 pmol/L), FT4 (0.5-100 $\mathrm{pmol} / \mathrm{L}), \mathrm{Tg}(0.1-1,000 \mathrm{ng} / \mathrm{ml}$ from $2015-2016$ and $0.04-500 \mathrm{ng} /$ $\mathrm{ml}$ from 2016), and TgAb (10-4,000 IU/ml). All the TSH, FT3, FT4, Tg, and TgAb levels were measured at the same laboratory in our hospital. Sera showing TgAb levels $>40 \mathrm{IU} / \mathrm{ml}$ were considered positive for DTC patients (13).

\section{Statistical Analysis}

All the continuous variables were tested for a normal distribution using the Kolmogorov-Smirnov (K-S) normality test. Next, the normally distributed variables were expressed as means \pm standard deviation $(\mathrm{M} \pm \mathrm{SD})$, and skewed variables were expressed as medians (minimum value, maximum value). The differences between the two groups were examined using unpaired two-tailed Student's t-test and the Mann-Whitney U test for normally and non-normally distributed parameters, respectively. Categorical variables were compared by chisquared test. Receiver operating characteristic (ROC) curves were used to evaluate the predictive effect of $\mathrm{TgAb}$ on the clinical outcome. Binary logistic regression was used to analyse the risk factors for the persistence/recurrence of disease. pValues $<0.05$ were considered statistically significant. All statistical analyses were performed using SPSS 25.0.

\section{RESULTS}

\section{Characteristics of the Patients}

Of the 1,686 consecutive DTC patients managed at our hospital from January 2015 to December 2017, 24 were excluded because preoperative $\mathrm{TgAb}$ was missing. Among the 1,662 patients, 393 (23.65\%) had a preoperative $\mathrm{TgAb}>40 \mathrm{IU} / \mathrm{ml}$. Subsequent exclusions comprised 81 cases in which the patients had missing essential indicators [missing $\mathrm{TgAb}$ in the follow-up $(\mathrm{n}=52)$, missing essential items to define the outcome $(\mathrm{n}=$ 29)], 20 cases in which a follow-up period was less than 2 years and 3 cases with lung metastasis at the initial diagnosis. Thus, the final cohort comprised 289 patients (Figure 1).

Most of the patients were female (85.12\%) and had classic PTC (96.54\%). The median age at diagnosis was 39 years (range: 16-74 years). The median lesion diameter was $1.2 \mathrm{~cm}$ (range: $0.3-6.0 \mathrm{~cm}$ ), and bilateral and multifocal lesions were present in 103 patients (35.64\%) and 118 patients (40.83\%), respectively. Extrathyroidal invasion was documented in 227 patients (78.55\%), of whom 198 (68.52\%) had capsular or fatty tissue invasion and $29(10.03 \%)$ had invasion of nerves, muscles, blood vessels, and the windpipe. A total of $250(86.51 \%)$ patients presented with lymph node involvement, with a median number of invaded lymph nodes of 4 (range: $0-36$ ). The ATA risk stratification was classified as low in 17 patients (5.88\%), intermediate in 222 patients (76.82\%), and high in 50 patients $(17.30 \%)$. The characteristics of the study cohort are indicated in Table $\mathbf{1 .}$

\section{Change Trends of Antithyroglobulin Antibody and Comparisons of the Levels of Antithyroglobulin Antibody at Different Time Points}

Change trends of TgAb in the four groups are displayed in Figure 2. In the tumour-free group (A), TgAb significantly decreased after surgery and ${ }^{131} \mathrm{I}$ therapy. Approximately 1 year after ${ }^{131} \mathrm{I}$ therapy (f), TgAb decreased slightly, and the concentration remained low. In the uncertain group (B), TgAb decreased after surgery and ${ }^{131} \mathrm{I}$ therapy, but not significantly. In the follow-up, TgAb declined slowly and remained positive. In the incomplete biochemical response (C) and structural disease (D) groups, no significant decrease in TgAb was

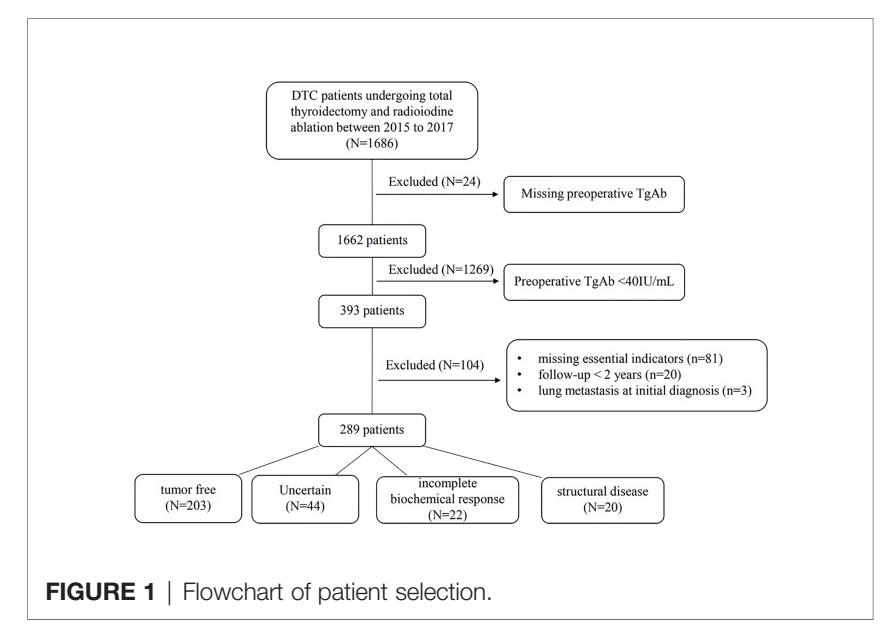


TABLE 1 | Characteristics of the study patients.

\begin{tabular}{|c|c|}
\hline Characteristics & Value \\
\hline No. of patients & 289 \\
\hline Age at diagnosis (years), median (range) & $39(16-74)$ \\
\hline$<55$ & 267 (92.39\%) \\
\hline$\geq 55$ & $22(7.61 \%)$ \\
\hline \multicolumn{2}{|l|}{ Sex } \\
\hline Male & 43 (14.88\%) \\
\hline Female & $246(85.12 \%)$ \\
\hline \multicolumn{2}{|l|}{ Surgery } \\
\hline$\Pi+$ central neck lymph node dissection & $189(65.40 \%)$ \\
\hline$\Pi+$ central and lateral neck lymph node dissection & $100(34.60 \%)$ \\
\hline \multicolumn{2}{|l|}{ Histology } \\
\hline Classic PTC & 279 (96.54\%) \\
\hline FV-PTC & $5(1.73 \%)$ \\
\hline DSV-PTC & $5(1.73 \%)$ \\
\hline Primary tumour size (cm), median (range) & $1.2(0.3-6.0)$ \\
\hline No. of LN metastases, median (range) & $4(0-36)$ \\
\hline Bilateral tumour & 103 (35.64\%) \\
\hline Multifocal tumour & $118(40.83 \%)$ \\
\hline Extrathyroidal extension & 227 (78.55\%) \\
\hline Microscopic & $198(68.52 \%)$ \\
\hline Macroscopic & $29(10.03 \%)$ \\
\hline \multicolumn{2}{|l|}{$\mathrm{T}$} \\
\hline $\mathrm{T} 1$ & $210(72.66 \%)$ \\
\hline $\mathrm{T} 2$ & $39(13.49 \%)$ \\
\hline T3 & $26(9.00 \%)$ \\
\hline $\mathrm{T} 4$ & $14(4.84 \%)$ \\
\hline \multicolumn{2}{|l|}{$\mathrm{N}$} \\
\hline NO & 39 (13.49\%) \\
\hline $\mathrm{N} 1 \mathrm{a}$ & $160(55.36 \%)$ \\
\hline N1b & $90(31.14 \%)$ \\
\hline \multicolumn{2}{|l|}{ Staging } \\
\hline \multicolumn{2}{|l|}{$<55$ years } \\
\hline I & 267 (92.39\%) \\
\hline$\|$ & $0(0 \%)$ \\
\hline \multicolumn{2}{|l|}{$\geq 55$ years } \\
\hline 1 & $3(1.04 \%)$ \\
\hline$\|$ & $14(4.84 \%)$ \\
\hline III & $3(1.04 \%)$ \\
\hline IV & $2(0.69 \%)$ \\
\hline \multicolumn{2}{|l|}{ Initial risk stratification } \\
\hline Low risk & $17(5.88 \%)$ \\
\hline Intermediate risk & $222(76.82 \%)$ \\
\hline High risk & $50(17.30 \%)$ \\
\hline \multicolumn{2}{|l|}{ Cumulative ${ }^{131} \mathrm{I}$-administered activities (mCi) } \\
\hline 30 & $20(6.92 \%)$ \\
\hline 50 & $8(2.77 \%)$ \\
\hline 100 & $244(84.43 \%)$ \\
\hline 150 & 17 (5.88\%) \\
\hline $\begin{array}{l}\text { Time interval between the first }{ }^{131} \text { I treatments to surgery } \\
\text { (months), median (range) }\end{array}$ & $4.0(0.8-12.0)$ \\
\hline \multicolumn{2}{|l|}{ Preoperative serum biomarkers level } \\
\hline TSH ( $\mu \mathrm{IU} / \mathrm{ml})$, median (range) & $\begin{array}{c}3.05(0.01- \\
52.99)\end{array}$ \\
\hline FT3 (pmol/L), median (range) & $4.82(3.27-8.53)$ \\
\hline FT4 (pmol/L), median (range) & $\begin{array}{c}16.31(9.63- \\
27.30)\end{array}$ \\
\hline $\operatorname{TgAb}(\mathrm{IU} / \mathrm{ml})$, median (range) & $\begin{array}{c}374.40(44.74- \\
4,000)\end{array}$ \\
\hline \multicolumn{2}{|l|}{ Follow-up information } \\
\hline Median follow-up (years), median (range) & $4.83(0.99-6.50)$ \\
\hline \multicolumn{2}{|l|}{ Final status } \\
\hline Tumour free & 203 (70.24\%) \\
\hline
\end{tabular}

TABLE 1 | Continued

\begin{tabular}{lc}
\hline Characteristics & Value \\
\hline Uncertain & $44(15.22 \%)$ \\
Incomplete biochemical response & $22(7.61 \%)$ \\
Structural disease & $20(6.92 \%)$ \\
\hline$T$, total thyroidectomy; PTC, papillary thyroid cancer; FV, follicular variant; DSV, diffuse \\
sclerosing variant; LN, Iymph node; TSH, thyroid-stimulating hormone; TgAb, \\
antithyroglobulin antibody.
\end{tabular}

observed after treatment, and the $\mathrm{TgAb}$ concentrations remained high or increased during the follow-up. In all groups except Group C, small increases were observed in the levels of TgAb at 1 month after ${ }^{131} \mathrm{I}$ therapy (d) compared with those before ${ }^{131}$ I therapy (c) (Table 2).

\section{Comparisons of the Variations in Antithyroglobulin Antibody Relative to the Preoperative Levels}

At every time point of follow-up after surgery, variations in $\mathrm{TgAb}$ relative to the preoperative levels were calculated as [(TgAb at every time point) - (preoperative $\operatorname{Tg} A b)] /($ preoperative $\operatorname{Tg} A b$ ). The variations in $\mathrm{TgAb}$ in Group A were significantly larger than those in Groups B, C, and D at every time point of the follow-up except "1 month after surgery" ( $p<0.001)$. The variations in $\mathrm{TgAb}$ in Group B were significantly larger than those in Group C at every time point except " 1 month after surgery" $(p<0.05)$. The variations in $\mathrm{TgAb}$ in Group $\mathrm{C}$ were significantly larger than those in Group D after ${ }^{131}$ I therapy $(\mathrm{p}<0.05)$ (Table 3).

\section{Prediction Efficacy of Variations in Antithyroglobulin Antibody Relative to the Preoperative Levels on Clinical Outcomes}

ROC analyses to predict the clinical outcomes at the end of follow-up were used in the following three comparisons: 1) tumour free with all others, 2) tumour free + uncertain group with incomplete biochemical response + structural disease group, and 3) the structural disease group with all other groups (Figure 3 and Table $\mathbf{4}$ ).

The area under the curve (AUC) values measured during ROC analyses showed good diagnostic values, and the p-value was $<0.001$ in most cases. Considering the AUC values, the prediction efficacy of the variations in TgAb on the clinical outcome of tumour free was better than on other clinical outcomes, and the prediction efficacy of the variations in $\mathrm{TgAb}$ on the clinical outcome of tumour free at time points after ${ }^{131} \mathrm{I}$ therapy was better than that before ${ }^{131} \mathrm{I}$ therapy.

\section{Predictors of the Tumour-Free Status at the End of Follow-Up in Univariate and Multivariate Analyses}

By applying univariate analyses, some risk factors were identified as predictors of tumour-free survival at the end of follow-up (Table 5). In multivariate analysis, variations in the $\operatorname{TgAb}$ at 1 year after ${ }^{131}$ I therapy $\geq-77.4 \%$, and 2 years after ${ }^{131}$ I therapy $\geq$ 
TABLE 2 | Levels of TgAb at every time point in the 4 groups.

\begin{tabular}{|c|c|c|c|c|}
\hline $\begin{array}{l}\text { TgAb (IU/ml), } \\
\text { median (range) }\end{array}$ & Tumour free (A) & Uncertain (B) & Incomplete biochemical response (C) & Structural disease (D) \\
\hline Preoperative (a) & $\begin{array}{c}320.60 \\
(44.92-4000)\end{array}$ & $\begin{array}{c}970.80 \\
(63.94-4000)\end{array}$ & $\begin{array}{c}541.90 \\
(44.74-4000)\end{array}$ & $\begin{array}{c}1148.85 \\
(88.74-4000)\end{array}$ \\
\hline 1 month after surgery (b) & $\begin{array}{c}190.60 \\
(30.44-4000)\end{array}$ & $\begin{array}{c}754.25 \\
(108.60-4000)\end{array}$ & $\begin{array}{c}431.95 \\
(38.27-4000)\end{array}$ & $\begin{array}{c}791.80 \\
(50.00-4000)\end{array}$ \\
\hline Before ${ }^{131}$ I therapy $(c)$ & $\begin{array}{c}54.12 \\
(13.28-1165)\end{array}$ & $\begin{array}{c}412.6 \\
(45.87-4000)\end{array}$ & $\begin{array}{c}418.7 \\
(32.91-4000)\end{array}$ & $\begin{array}{c}563.25 \\
(10.00-3916)\end{array}$ \\
\hline 1 month after ${ }^{131}$ I therapy $(d)$ & $\begin{array}{c}67.17 \\
(10.00-1245)\end{array}$ & $\begin{array}{c}454.75 \\
(51.00-4000)\end{array}$ & $\begin{array}{c}385.50 \\
(31.24-4000)\end{array}$ & $\begin{array}{c}757.70 \\
(15.00-4000)\end{array}$ \\
\hline 6 months after ${ }^{131} \mathrm{I}$ therapy $(\mathrm{e})$ & $\begin{array}{c}30.00 \\
(10.00-267.00)\end{array}$ & $\begin{array}{c}373.95 \\
(34.48-4000)\end{array}$ & $\begin{array}{c}364.30 \\
(35.76-4000)\end{array}$ & $\begin{array}{c}574.70 \\
(10.00-4000)\end{array}$ \\
\hline 1 year after ${ }^{131}$ I therapy $(f)$ & $\begin{array}{c}19.48 \\
(10.00-172.10)\end{array}$ & $\begin{array}{c}254.05 \\
(42.48-4000)\end{array}$ & $\begin{array}{c}716 \\
(38.59-4000)\end{array}$ & $\begin{array}{c}437.40 \\
(10.00-4000)\end{array}$ \\
\hline 2 years after ${ }^{131}$ I therapy $(\mathrm{g})$ & $\begin{array}{c}14.90 \\
(10.00-307.70)\end{array}$ & $\begin{array}{c}260.00 \\
(40.74-4000)\end{array}$ & $\begin{array}{c}900.35 \\
(55.59-4000)\end{array}$ & $\begin{array}{c}494.00 \\
(16.81-4000)\end{array}$ \\
\hline 3 years after ${ }^{131}$ I therapy $(h)$ & $\begin{array}{c}13.93 \\
(10.00-123.50)\end{array}$ & $\begin{array}{c}192.85 \\
(40.00-3672)\end{array}$ & $\begin{array}{c}1163.00 \\
(36.11-4000)\end{array}$ & $\begin{array}{c}317.7 \\
(15.18-4000)\end{array}$ \\
\hline 4 years after ${ }^{131}$ I therapy (i) & $\begin{array}{c}12.68 \\
(10.00-56.86)\end{array}$ & $\begin{array}{c}171.75 \\
(41.30-1906)\end{array}$ & $\begin{array}{c}1075.00 \\
(29.30-4000)\end{array}$ & $\begin{array}{c}709.40 \\
(22.55-4000)\end{array}$ \\
\hline 5 years after ${ }^{131}$ I therapy (j) & $\begin{array}{c}12.40 \\
(10.00-39.00)\end{array}$ & $\begin{array}{c}150.00 \\
(45.10-1547)\end{array}$ & $\begin{array}{c}1520.00 \\
(130.80-4000)\end{array}$ & a \\
\hline 6 years after ${ }^{131}$ I therapy $(k)$ & $\begin{array}{c}13.00 \\
(10.00-39.00)\end{array}$ & $\begin{array}{c}123.5 \\
(50.30-1043)\end{array}$ & $\begin{array}{c}1300 \\
(290.00-1300)\end{array}$ & b \\
\hline
\end{tabular}

a, b: All patients in Group D reached the follow-up end $<5$ years after ${ }^{131}$ I therapy.

\begin{tabular}{|c|c|c|c|c|c|c|}
\hline \multirow[t]{2}{*}{ TgAb (IU/ml) } & A-B & $A-C$ & A-D & $B-C$ & B-D & C-D \\
\hline & \multicolumn{6}{|c|}{ p-Values } \\
\hline Preoperative & $<0.001$ & 0.052 & $<0.001$ & 0.079 & 0.550 & 0.068 \\
\hline 1 month after surgery & $<0.001$ & 0.003 & $<0.001$ & 0.145 & 0.571 & 0.160 \\
\hline Before ${ }^{131}$ I therapy & $<0.001$ & $<0.001$ & $<0.001$ & 0.559 & 0.290 & 0.212 \\
\hline 1 month after ${ }^{131}$ | therapy & $<0.001$ & $<0.001$ & $<0.001$ & 0.568 & 0.108 & 0.134 \\
\hline 6 months after ${ }^{131}$ I therapy & $<0.001$ & $<0.001$ & $<0.001$ & 0.729 & 0.221 & 0.505 \\
\hline 1 year after ${ }^{131} \mid$ therapy & $<0.001$ & $<0.001$ & $<0.001$ & 0.094 & 0.164 & 0.529 \\
\hline 2 years after ${ }^{131}$ I therapy & $<0.001$ & $<0.001$ & $<0.001$ & 0.004 & 0.208 & 0.236 \\
\hline 3 years after ${ }^{131} \mid$ therapy & $<0.001$ & $<0.001$ & $<0.001$ & $<0.001$ & 0.482 & 0.060 \\
\hline 4 years after ${ }^{131}$ I therapy & $<0.001$ & $<0.001$ & $<0.001$ & $<0.001$ & 0.383 & 0.505 \\
\hline 5 years after ${ }^{131}$ I therapy & $<0.001$ & $<0.001$ & - & 0.004 & - & - \\
\hline 6 years after ${ }^{131} I$ therapy & $<0.001$ & 0.004 & - & 0.03 & - & - \\
\hline
\end{tabular}

\begin{tabular}{|c|c|c|c|c|c|c|c|c|c|c|}
\hline \multicolumn{11}{|c|}{$\mathrm{p}$-Values of the time point comparisons } \\
\hline \multirow[t]{2}{*}{ TgAb (IU/ml) } & $a-b$ & $b-c$ & $c-d$ & d-e & $e-f$ & $f-g$ & g-h & $h-i$ & $\mathbf{i}-\mathbf{j}$ & j-k \\
\hline & \multicolumn{10}{|c|}{ p-Value } \\
\hline Group A & $<0.01$ & $<0.01$ & 0.235 & $<0.01$ & $<0.01$ & $<0.01$ & 0.046 & 0.167 & 0.693 & 0.422 \\
\hline Group B & 0.146 & 0.022 & 0.689 & 0.191 & 0.284 & 0.686 & 0.526 & 0.340 & 0.518 & 0.836 \\
\hline Group C & 0.707 & 0.573 & 0.888 & 0.888 & 0.439 & 0.557 & 0.496 & 0.977 & 0.516 & 0.905 \\
\hline Group D & 0.529 & 0.253 & 0.565 & 0.414 & 0.738 & 0.947 & 0.650 & 0.877 & - & - \\
\hline
\end{tabular}

TgAb, antithyroglobulin antibody.

$-88.6 \%$ were independent predictive factors for a tumour-free status at the end of follow-up (Table 6).

\section{Integrating the Variation in Antithyroglobulin Antibody With American Thyroid Association Risk Categories}

In our study cohort, when patients were stratified according to the ATA categories, the disease-free status declined progressively, with the level of initial risk estimated at $82.35 \%$ in the low-risk patients, $75.68 \%$ in the intermediate-risk patients, and $42.0 \%$ in the high-risk patients.

When the variation of $\mathrm{TgAb} \geq-77.9 \%$ at 6 months after ${ }^{131} \mathrm{I}$ therapy was incorporated as a variable in the ATA categories, both intermediate- and high-risk patients showed a significantly increased chance of being tumour free (from $75.68 \%$ to $91.28 \%$ and $42.0 \%$ to $78.26 \%$, respectively). 

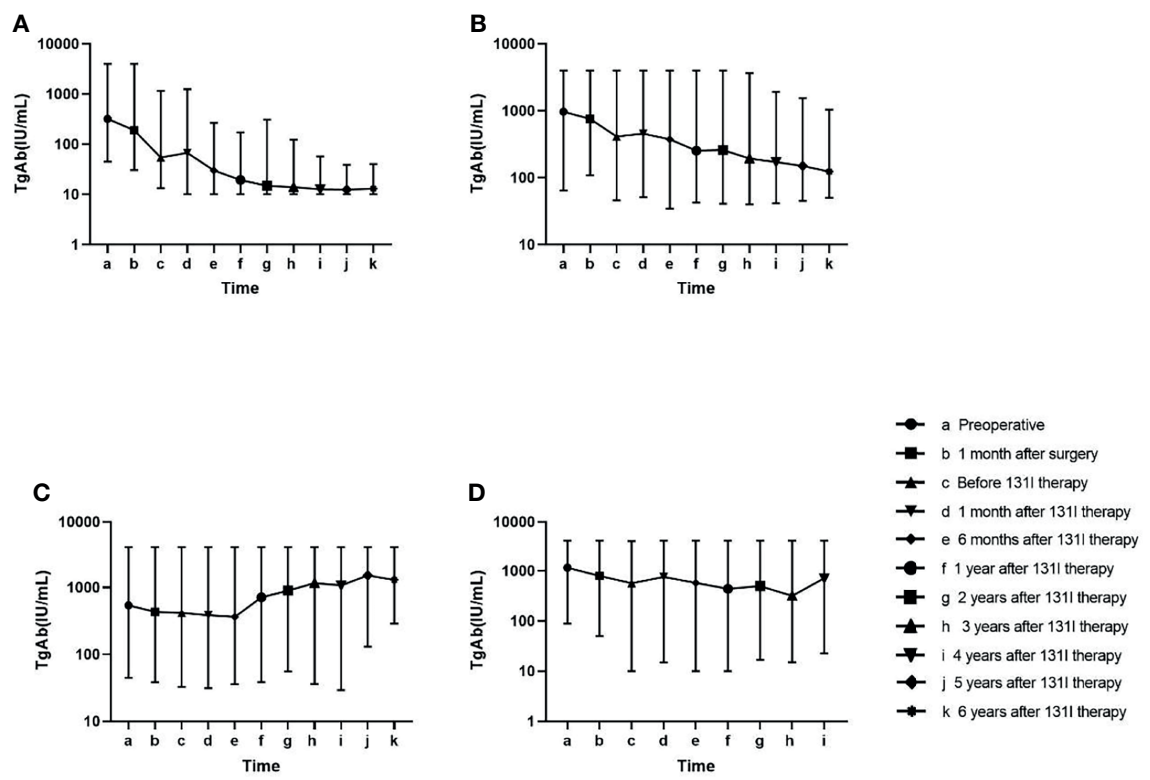

FIGURE 2 | Change in the antithyroglobulin antibody (TgAb) level in the follow-up of four groups. Patients in Group (A) had lower TgAb concentrations than the other three groups at every time point in the follow-up ( $p<0.05)$. Patients in Group (B) had lower TgAb concentrations than those in Group (C) at the late follow-up $(p<0.05)$. No significant difference was found in the TgAb values at other time points among Groups (B-D) (Table 2).

Similarly, when the variation of $\mathrm{TgAb} \geq-88.6 \%$ at 2 years after ${ }^{131}$ I therapy was incorporated as a variable in the ATA categories, both intermediate- and high-risk patients also showed a significantly increased chance of being tumour free (from $75.68 \%$ to $93.88 \%$ and $42.0 \%$ to $82.61 \%$, respectively) (Table 7 ).

\section{DISCUSSION}

Usually, $\operatorname{TgAb}$ is a serum biomarker for the diagnosis and followup of thyroid autoimmune diseases. However, because of the following three characteristics, TgAb has been more valued as a prognostic indicator for DTC patients: 1) approximately $20 \%$

TABLE 3 | Comparison of the variations in TgAb relative to the preoperative levels.

\begin{tabular}{|c|c|c|c|c|c|c|}
\hline Variation in $\mathrm{TgAb}$ relative to the preoperative level (\%) & Tumour free $(A)$ & Uncertain (B) & \multicolumn{2}{|c|}{$\begin{array}{l}\text { Incomplete biochemi- } \\
\text { cal response (C) }\end{array}$} & \multicolumn{2}{|c|}{$\begin{array}{l}\text { Structural } \\
\text { disease (D) }\end{array}$} \\
\hline 1 month after surgery & $-34.74(-92.93$ to 3.99$)$ & -22.27 (-74.51 to 90.49) & \multicolumn{2}{|c|}{$-7.46(-73.50$ to 75.26$)$} & \multicolumn{2}{|c|}{$\begin{array}{c}-18.90(-66.03 \text { to } \\
39.76)\end{array}$} \\
\hline Before ${ }^{131}$ I therapy & -76.34 (-97.13 to 2.63$)$ & $-49.71(-90.51$ to 14.67$)$ & \multicolumn{2}{|c|}{$-19.33(-87.27$ to 57.50$)$} & \multicolumn{2}{|c|}{$\begin{array}{c}-43.69(-94.65 \text { to } \\
63.98)\end{array}$} \\
\hline 6 months after ${ }^{131}$ I therapy & $-89.14(-98.39$ to -18.95$)$ & $-65.11(-94.29$ to 112.54$)$ & \multicolumn{2}{|c|}{$-9.16(-85.85$ to 117.01$)$} & \multicolumn{2}{|c|}{$\begin{array}{c}-50.74(-98.62 \text { to } \\
670.64)\end{array}$} \\
\hline 1 year after ${ }^{131} \mid$ therapy & $-93.39(-99.27$ to -31.79$)$ & $-67.53(-96.72$ to 293.96$)$ & \multicolumn{2}{|c|}{0 (-83.24 to 31.99$)$} & \multicolumn{2}{|c|}{$\begin{array}{c}-67.70(-99.53 \text { to } \\
656.72)\end{array}$} \\
\hline 2 years after ${ }^{131}$ I therapy & $-94.84(-99.49$ to -31.96$)$ & -67.98 (-96.25 to 577.82) & \multicolumn{2}{|c|}{$7.34(-82.60$ to 214.31$)$} & \multicolumn{2}{|c|}{$\begin{array}{c}-72.73(-99.58 \text { to } \\
656.72) \\
\end{array}$} \\
\hline \multicolumn{7}{|c|}{$\mathrm{p}$-Values of comparisons of groups } \\
\hline \multirow[t]{2}{*}{ Variation in $\mathrm{TgAb}$ relative to the preoperative level } & A-B & A-C & A-D & B-C & B-D & C-D \\
\hline & \multicolumn{6}{|c|}{ p-Value } \\
\hline 1 month after surgery & 0.064 & 0.001 & 0.080 & 0.124 & 0.794 & 0.233 \\
\hline Before ${ }^{131}$ I therapy & $<0.001$ & $<0.001$ & $<0.001$ & 0.009 & 0.271 & 0.273 \\
\hline 6 months after ${ }^{131}$ I therapy & $<0.001$ & $<0.001$ & $<0.001$ & 0.001 & 0.567 & 0.028 \\
\hline 1 year after ${ }^{131}$ I therapy & $<0.001$ & $<0.001$ & $<0.001$ & $<0.001$ & 0.487 & 0.011 \\
\hline 2 years after ${ }^{131} I$ therapy & $<0.001$ & $<0.001$ & $<0.001$ & $<0.001$ & 0.483 & 0.003 \\
\hline
\end{tabular}

$\operatorname{TgAb}$, antithyroglobulin antibody. 

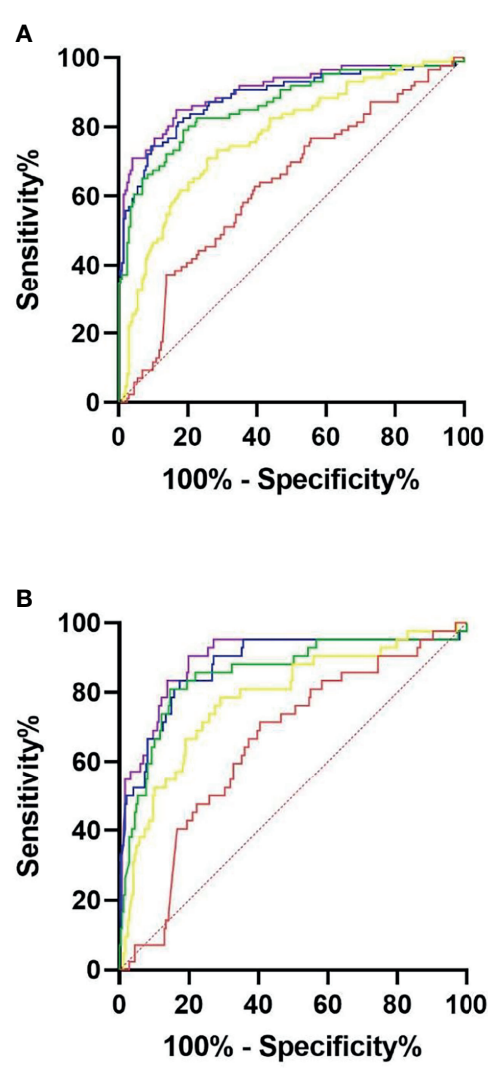

C

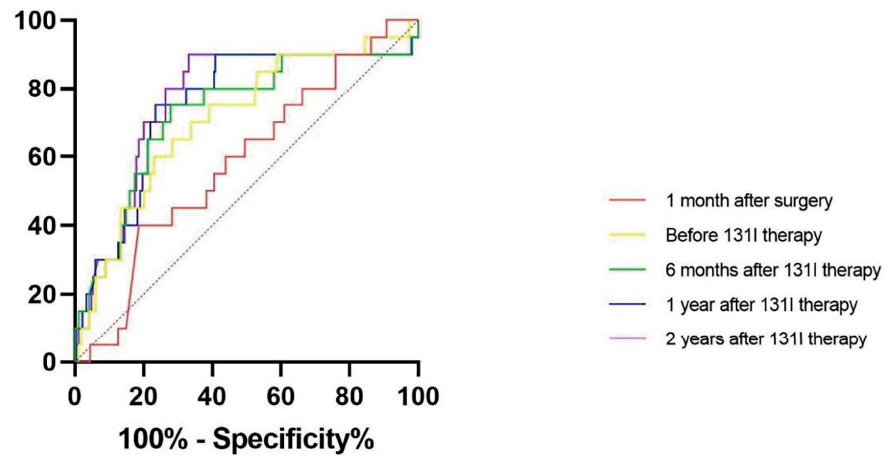

FIGURE 3 | Diagnostic benefit of the variations in antithyroglobulin antibody (TgAb) relative to the preoperative levels in predicting the clinical outcome during receiver operating characteristic $(\mathrm{ROC})$ analyses. (A) Tumour-free versus uncertain + incomplete biochemical response + structural disease at the end of follow-up. (B) Tumour free + uncertain versus incomplete biochemical response + structural disease at the end of follow-up. (C) Tumour-free + uncertain + incomplete biochemical response versus structural disease at the end of follow-up.

$\sim 30 \%$ of patients with DTC are TgAb positive on initial followpostoperative assessment $(14,15) ; 2)$ the presence of $\operatorname{TgAb}$ compromises the authenticity of $\mathrm{Tg}$, and it is recommended to measure the level of TgAb during Tg measurement; 3) ideally, for DTC patients who undergo TT and ${ }^{131} \mathrm{I}$ therapy, the TgAb level should decrease until undetectable without stimulation of Tg. Many cross-sectional studies focus on the relationship between the level of TgAb and DTC, but the prognostic significance of the
TgAb status (positive/negative) is unclear (16). Compared with observing $\mathrm{TgAb}$ at a single time point, TgAb trends appear to have more clinical usefulness as a surrogate tumour marker in the surveillance of TgAb-positive DTC patients (16) because the trend of $\mathrm{TgAb}$ is associated with higher tumour metabolism (17). Most existing studies have concluded that an increase in $\mathrm{TgAb}$ can indicate disease presence (18-20), and some studies empirically used a reduction of $50 \%$ of $\mathrm{TgAb}$ to group subjects, 
TABLE 4 | Diagnostic benefit of variations in TgAb relative to the preoperative levels in predicting the clinical outcome (by ROC analyses).

Tumour free versus uncertain + incomplete biochemical response + structural disease at the end of follow-up.

\begin{tabular}{|c|c|c|c|c|c|c|c|c|}
\hline Variation in $\mathrm{TgAb}$ relative to the preoperative level & AUC & p-Value & Cut-off & Sens $\%$ & Spec\% & PPV\% & NPV\% & DA $\%$ \\
\hline 1 month after surgery & 0.628 & 0.001 & $-24.2 \%$ & 62.8 & 60.6 & 40.3 & 79.2 & 61.1 \\
\hline Before ${ }^{131}$ I therapy & 0.771 & $<0.001$ & $-63.4 \%$ & 70.9 & 74.4 & 43.8 & 88.2 & 63.3 \\
\hline 6 months after ${ }^{131}$ I therapy & 0.862 & $<0.001$ & $-77.9 \%$ & 79.1 & 81.3 & 64.2 & 90.2 & 80.6 \\
\hline 1 year after ${ }^{131}$ I therapy & 0.884 & $<0.001$ & $-77.4 \%$ & 74.4 & 90.6 & 77.1 & 89.3 & 85.8 \\
\hline 2 years after ${ }^{131} \mathrm{I}$ therapy & 0.901 & $<0.001$ & $-88.6 \%$ & 84.9 & 83.3 & 67.3 & 91.4 & 82.7 \\
\hline
\end{tabular}

Tumour free +uncertain versus incomplete biochemical response + structural disease at the end of follow-up.

\begin{tabular}{|c|c|c|c|c|c|c|c|c|}
\hline Variation in $\mathrm{TgAb}$ relative to the preoperative level & AUC & p-Value & Cut-off & Sens $\%$ & Spec\% & PPV\% & NPV\% & DA $\%$ \\
\hline 1 month after surgery & 0.652 & 0.002 & $-22.9 \%$ & 71.4 & 59.5 & 23.1 & 92.5 & 61.2 \\
\hline Before ${ }^{131}$ I therapy & 0.782 & $<0.001$ & $-60.4 \%$ & 78.6 & 70.9 & 31.4 & 95.1 & 72.0 \\
\hline 6 months after ${ }^{131}$ I therapy & 0.853 & $<0.001$ & $-65.5 \%$ & 81.0 & 85.4 & 48.6 & 96.3 & 84.8 \\
\hline 1 year after ${ }^{131}$ I therapy & 0.877 & $<0.001$ & $-75.4 \%$ & 83.3 & 82.6 & 44.9 & 96.7 & 82.7 \\
\hline 2 years after ${ }^{131}$ I therapy & 0.894 & $<0.001$ & $-83.8 \%$ & 90.5 & 80.2 & 43,7 & 98.0 & 81.7 \\
\hline
\end{tabular}

Tumour free +uncertain versus incomplete biochemical response + structural disease at the end of follow-up.

\begin{tabular}{|c|c|c|c|c|c|c|c|c|}
\hline Variation in $\mathrm{TgAb}$ relative to the preoperative level & AUC & p-Value & Cut-off & Sens $\%$ & Spec\% & PPV\% & NPV\% & DA $\%$ \\
\hline 1 month after surgery & 0.584 & 0.209 & $-22.9 \%$ & 60.0 & 56.1 & 9.2 & 95.0 & 56.4 \\
\hline Before ${ }^{131}$ I therapy & 0.710 & 0.002 & $-45.6 \%$ & 60.0 & 77.0 & 12.7 & 94.5 & 74.7 \\
\hline 6 months after ${ }^{131}$ I therapy & 0.728 & 0.001 & $-73.7 \%$ & 75.0 & 72.1 & 16.7 & 97.5 & 72.3 \\
\hline 1 year after ${ }^{131}$ I therapy & 0.750 & $<0.001$ & $-75.4 \%$ & 75.0 & 76.6 & 19.2 & 97.6 & 76.5 \\
\hline 2 years after ${ }^{131}$ I therapy & 0.764 & $<0.001$ & $-88.6 \%$ & 90.0 & 66.9 & 16.8 & 98.9 & 68.5 \\
\hline
\end{tabular}

$T g A b$, antithyroglobulin antibody; ROC, receiver operating characteristic; AUC, area under the curve; PPV, positive predictive value; NPV, negative predictive value; DA, diagnostic accuracy.

finding that a reduction $>50 \%$ can represent a good prognosis (21). Based on these studies, our study described overall TgAb change trends after surgery in preoperative TgAb-positive DTC patients and compared changes in TgAb among patients with different clinical outcomes, aiming to further elucidate the prognostic value of $\mathrm{TgAb}$.

The current study demonstrated the prognostic value of variations in $\mathrm{TgAb}$ relative to the preoperative level after surgery in predicting clinical outcomes. In particular, variations of TgAb at 6 months after ${ }^{131}$ I therapy $\geq-77.9 \%$ and at 2 years after ${ }^{131} \mathrm{I}$ therapy $\geq-88.6 \%$ were excellent predictors of tumour-free survival, with negative predictive values (NPVs) as high as $90.2 \%$ and $91.4 \%$, respectively. Our study indicated that the integration of the variations of TgAb into the ATA categories more effectively predicted the clinical outcome of tumour-free patients. Additionally, 23.65\% of DTC patients had positive preoperative $\mathrm{TgAb}$, which was comparable with the $23.2 \%$ reported by Lee et al. (22). Using the change in TgAb during follow-up, we found that TgAb in the tumour-free group declined significantly after surgery and ${ }^{131}$ I therapy, but we did not observe this phenomenon in the other three groups. Additionally, after 1-2 years of ${ }^{131} \mathrm{I}$ therapy, the $\mathrm{TgAb}$ of patients in the tumour-free group stabilised at a very low level. However, in the uncertain group, the TgAb decline was slow. In the incomplete biochemical response group, TgAb increased. In the structural disease group, the TgAb levels continued to be high and positive. This result was consistent with the general view that persistent/increasing trends in TgAb were associated with a compromised DTC prognosis (16, 23). Additionally, we observed a slight rise in TgAb at 1 month after ${ }^{131} \mathrm{I}$ therapy in most groups, likely attributed to the response to an acute increase in Tg antigen after ${ }^{131}$ I therapy (24).
In this study, to predict the clinical outcomes, five variations in $\mathrm{TgAb}-1$ month after surgery, before ${ }^{131} \mathrm{I}$ therapy, and 6 months, 1 year, and 2 years after ${ }^{131} \mathrm{I}$ therapy-were evaluated in 289 preoperative TgAb-positive DTC patients. The AUC values obtained in the ROC analysis were mostly good ( $>0.75$ ); in onethird of the cases, they were excellent $(>0.85)$. The variation of $\mathrm{TgAb}>-88.6 \%$ at 2 years after ${ }^{131}$ I therapy showed the highest AUC value (0.901) to predict a tumour-free status, with $84.9 \%$ sensitivity, $83.3 \%$ specificity, $82.7 \%$ diagnostic accuracy, $91.4 \%$ $\mathrm{NPV}$, and $67.3 \%$ positive predictive value (PPV). For the good performance of the variation of $\mathrm{TgAb}$ in predicting a diseasefree status, we combined the three groups with the tumourfree group into the non-disease-free group, and we found that the variations of $\operatorname{TgAb}>-77.4 \%$ at 1 year after ${ }^{131} \mathrm{I}$ therapy, and $\mathrm{TgAb}>-88.6 \%$ at 2 years after ${ }^{131} \mathrm{I}$ therapy were independent predictive factors for a tumour-free status at the end of follow-up. We also combined the subgroups because both the uncertain clinical outcome and incomplete biochemical response reflect that residual cancer could not be ruled out.

The prognostic role of $\mathrm{TgAb}$ has been studied in some studies $(11,12,15,25)$. Although the studies differed in patient grouping, the authors found that the trend and reduction of $\mathrm{TgAb}>50 \%$ are critical prognostic factors. In our study, the cut-off values of TgAb reduction at different time points in the follow-up were determined by ROC analysis and were generally consistent with other studies. The major advantage of our study is that a relatively large population (considering that $\mathrm{TgAb}$-positive patients account for only $20 \%$ $\sim 30 \%$ of DTC patients) undergoing standardised diagnostic and therapeutic processes in West China Hospital (third-class 
TABLE 5 | Univariate analysis of predictors of a tumour-free clinical outcome.

\begin{tabular}{|c|c|c|c|}
\hline Characteristics & Disease free & Non-disease free & $\mathbf{p}$ \\
\hline No. of patients & 203 & 86 & \\
\hline \multicolumn{3}{|l|}{ Age at diagnosis (years), median (range) } & 0.791 \\
\hline$<55$ & $187(92.12 \%)$ & $80(93.02 \%)$ & \\
\hline$\geq 55$ & $16(7.88 \%)$ & $6(6.98 \%)$ & \\
\hline \multicolumn{3}{|l|}{ Sex } & 0.025 \\
\hline Male & $24(11.82 \%)$ & $19(22.09 \%)$ & \\
\hline Female & $179(88.18 \%)$ & $67(77.91 \%)$ & \\
\hline \multicolumn{3}{|l|}{ Surgery } & 0.006 \\
\hline$\Pi T+$ central neck lymph node dissection & $143(70.44 \%)$ & $46(53.49 \%)$ & \\
\hline$\Pi T+$ central and lateral neck lymph node dissection & $60(29.56 \%)$ & 40 (46.51\%) & \\
\hline \multicolumn{3}{|l|}{ Histology } & 0.79 \\
\hline Classic PTC & 195 (96.06\%) & $84(97.67 \%)$ & \\
\hline FV-PTC & $4(1.97 \%)$ & $1(1.16 \%)$ & \\
\hline DSV-PTC & 4 (1.97\%) & $1(1.16 \%)$ & \\
\hline Primary tumour size (cm), median (range) & $1.0(0.3-6.0)$ & $1.7(0.5-6.0)$ & $<0.001$ \\
\hline No. of LN metastases, median (range) & $3(0-36)$ & $6(0-35)$ & $<0.001$ \\
\hline Bilateral tumour & 73 (35.96\%) & $30(34.88 \%)$ & 0.861 \\
\hline Multifocal tumour & 83 (40.89\%) & $35(40.70 \%)$ & 0.976 \\
\hline \multicolumn{3}{|l|}{ Extrathyroidal extension } & $<0.001$ \\
\hline No invasion & 47 (23.15\%) & $15(17.44)$ & \\
\hline Microscopic & $150(73.89 \%)$ & $48(55.81 \%)$ & \\
\hline Macroscopic & $6(2.96 \%)$ & $23(26.74 \%)$ & \\
\hline \multicolumn{3}{|l|}{$\mathrm{T}$} & $<0.001$ \\
\hline $\mathrm{T} 1$ & 169 (83.25\%) & $41(47.67 \%)$ & \\
\hline $\mathrm{T} 2$ & $25(12.32 \%)$ & $14(16.28 \%)$ & \\
\hline T3 & $8(3.94 \%)$ & $18(20.93 \%)$ & \\
\hline T4 & $1(0.49 \%)$ & $13(15.12 \%)$ & \\
\hline \multicolumn{3}{|r|}{ 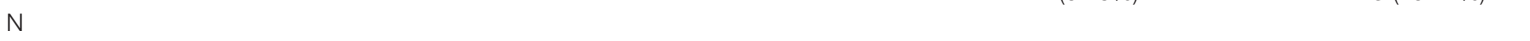 } & $<0.001$ \\
\hline NO & $34(16.75 \%)$ & $5(5.81 \%)$ & \\
\hline $\mathrm{N} 1 \mathrm{a}$ & $119(58.62 \%)$ & $41(47.67 \%)$ & \\
\hline N1b & $50(24.63 \%)$ & 40 (46.51\%) & \\
\hline \multicolumn{4}{|l|}{ Staging } \\
\hline \multicolumn{4}{|l|}{$<55$ years } \\
\hline I & 187 (92.12\%) & $80(93.02 \%)$ & \\
\hline 1 & $0(0)$ & $0(0)$ & \\
\hline \multicolumn{3}{|l|}{$\geq 55$ years } & $<0.001$ \\
\hline 1 & $3(1.48 \%)$ & $0(0)$ & \\
\hline$\|$ & $13(6.40 \%)$ & $1(1.16 \%)$ & \\
\hline III & $0(0)$ & $3(3.49 \%)$ & \\
\hline IV & $0(0)$ & $2(2.33 \%)$ & \\
\hline \multicolumn{3}{|l|}{ Initial risk stratification } & $<0.001$ \\
\hline Low risk & $14(6.90 \%)$ & $3(3.49 \%)$ & \\
\hline Intermediate risk & $168(82.76 \%)$ & $54(62.79 \%)$ & \\
\hline High risk & $21(10.34 \%)$ & 29 (33.72\%) & \\
\hline \multicolumn{3}{|l|}{ Cumulative ${ }^{131} \mathrm{I}$-administered activities (mCi) } & 0.337 \\
\hline 30 & $17(8.37 \%)$ & $3(3.49 \%)$ & \\
\hline 50 & 5 (2.46\%) & $3(3.49 \%)$ & \\
\hline 100 & $171(84.24 \%)$ & $73(84.88 \%)$ & \\
\hline 150 & $10(4.93 \%)$ & 7 (8.14\%) & \\
\hline Time interval between the first ${ }^{131}$ I treatments to surgery (months), median (range) & $4.1(1.2-12.0)$ & $4.0(0.8-12.0)$ & 0.463 \\
\hline \multicolumn{4}{|l|}{ Preoperative serum biomarkers level } \\
\hline \multirow[t]{2}{*}{$\mathrm{TSH}(\mu \mathrm{IU} / \mathrm{ml})$, median (range) } & 3.08 & 2.99 & 0.388 \\
\hline & $(0.01-28.15)$ & $(0.01-52.99)$ & \\
\hline \multirow[t]{2}{*}{ FT3 (pmol/L), median (range) } & 4.85 & 4.80 & 0.526 \\
\hline & (3.27-8.53) & (3.32-6.81) & \\
\hline \multirow[t]{2}{*}{ FT4 (pmol/L), median (range) } & 16.25 & 16.34 & 0.723 \\
\hline & $(9.63-27.30)$ & (12.30-24.48) & \\
\hline \multirow[t]{2}{*}{ TgAb (IU/ml), median (range) } & 320.60 & 942.45 & $<0.001$ \\
\hline & $(44.92-4000)$ & $(44.74-4000)$ & \\
\hline
\end{tabular}

PTC, papillary thyroid cancer; FV, follicular variant; DSV, diffuse sclerosing variant; LN, lymph node; TSH, thyroid-stimulating hormone; TgAb, antithyroglobulin antibody.

hospital) could be evaluated. Additionally, a strength of our study is that the changes of $\mathrm{TgAb}$ during follow-up are shown intuitively, providing new insight into the prognostic value of $\mathrm{TgAb}$ in the clinical outcomes and integrating the variation of $\mathrm{TgAb}$ into the ATA risk categories to increase the chance of having a tumour-free status in intermediate- and highrisk patients.

However, our study has limitations. First, this study has a single-centre and retrospective study design, which may lead to selection biases. Second, although a median follow-up period of 
TABLE 6 | Multivariate analysis of predictors of a tumour-free clinical outcome.

\begin{tabular}{|c|c|c|c|}
\hline Parameters & OR & $95 \% \mathrm{Cl}$ & $\mathbf{P}$ \\
\hline \multicolumn{4}{|l|}{ Sex } \\
\hline Male & 1 & & \\
\hline Female & 0.355 & $0.111-1.135$ & 0.081 \\
\hline \multicolumn{4}{|l|}{ Surgery } \\
\hline$\Pi+$ central neck lymph node dissection & 1 & & \\
\hline$\Pi++$ central and lateral neck lymph node dissection & 0.677 & $0.139-3.288$ & 0.628 \\
\hline \multicolumn{4}{|l|}{ Extrathyroidal extension } \\
\hline No invasion & 1 & & \\
\hline Microscopic & 1.703 & $0.097-29.976$ & 0.716 \\
\hline Macroscopic & 0.890 & $0.061-13.048$ & 0.932 \\
\hline \multicolumn{4}{|l|}{$\mathrm{T}$} \\
\hline T1 & 1 & & \\
\hline $\mathrm{T} 2$ & 0.016 & $0.000-0.876$ & 0.043 \\
\hline T3 & 0.060 & $0.001-3.207$ & 0.166 \\
\hline $\mathrm{T} 4$ & 0.247 & $0.012-5.162$ & 0.367 \\
\hline \multicolumn{4}{|l|}{$\mathrm{N}$} \\
\hline NO & 1 & & \\
\hline $\mathrm{N} 1 \mathrm{a}$ & 0.820 & $0.100-6.732$ & 0.854 \\
\hline $\mathrm{N} 1 \mathrm{~b}$ & 1.120 & $0.212-5.925$ & 0.894 \\
\hline \multicolumn{4}{|l|}{ Initial risk stratification } \\
\hline Low risk & 1 & & \\
\hline Intermediate risk & 0.283 & $0.025-3.234$ & 0.310 \\
\hline High risk & 0.461 & $0.124-1.712$ & 0.247 \\
\hline \multicolumn{4}{|l|}{ The variation of $\mathrm{TgAb}$ relative to preoperative level } \\
\hline Before ${ }^{131}$ I therapy $<-63.4 \%$ & 1 & & \\
\hline Before ${ }^{131}$ I therapy $\geq-63.4 \%$ & 0.600 & $0.193-1.865$ & 0.377 \\
\hline 6 months after ${ }^{131}$ I therapy $<-77.9 \%$ & 1 & & \\
\hline 6 months after ${ }^{131}$ I therapy $\geq-77.9 \%$ & 3.098 & $0.975-9.845$ & 0.055 \\
\hline 1 year after ${ }^{131}$ I therapy $<-77.4 \%$ & 1 & & \\
\hline 1 year after ${ }^{131}$ I therapy $\geq-77.4 \%$ & 4.875 & $1.651-14.395$ & 0.004 \\
\hline 2 years after ${ }^{131}$ I therapy $<-88.6 \%$ & 1 & & \\
\hline 2 years after ${ }^{131}$ I therapy $\geq-88.6 \%$ & 9.919 & $3.185-30.885$ & $<0.001$ \\
\hline
\end{tabular}

OR, odds ratio; $\pi$, total thyroidectomy; TgAb, antithyroglobulin antibody.

TABLE 7 | Restratification of the ATA risk categories according to the variation in TgAb relative to the preoperative level.

\begin{tabular}{|c|c|c|c|}
\hline \multirow[t]{2}{*}{ Disease free } & \multicolumn{3}{|c|}{ ATA initial risk of recurrence classification $(n=289)$} \\
\hline & Low $(n=17)$ & Intermediate $(\mathbf{n}=\mathbf{2 2 2})$ & High $(n=50)$ \\
\hline & $82.35 \%$ & $75.68 \%$ & $42.0 \%$ \\
\hline & $(14 / 17)$ & 168/222) & $(21 / 50)$ \\
\hline \multicolumn{4}{|c|}{ Variation in $\mathrm{TgAb}$ at 6 months after ${ }^{131}$ I therapy } \\
\hline \multirow[t]{2}{*}{$\geq-77.9 \%(n=184)$} & $91.67 \%$ & $91.28 \%$ & $78.26 \%$ \\
\hline & $(11 / 12)$ & $(136 / 149)$ & $(18 / 23)$ \\
\hline \multirow[t]{2}{*}{$<-77.9 \%(n=105)$} & $60 \%$ & $43.84 \%$ & $11.11 \%$ \\
\hline & $(3 / 5)$ & $(32 / 73)$ & $(3 / 27)$ \\
\hline $\mathrm{p}$ & 0.474 & $<0.001$ & 0.004 \\
\hline \multicolumn{4}{|c|}{ Variation in TgAb at 2 years after ${ }^{131}$ I therapy } \\
\hline \multirow[t]{2}{*}{$\geq-88.6 \%(n=182)$} & $100 \%$ & $93.88 \%$ & $82.61 \%$ \\
\hline & $(12 / 12)$ & $(138 / 147)$ & $(19 / 23)$ \\
\hline \multirow[t]{2}{*}{$<-88.6 \%(n=107)$} & $40 \%$ & $40 \%$ & $7.41 \%$ \\
\hline & $(2 / 5)$ & $(30 / 75)$ & $(2 / 27)$ \\
\hline$p$ & 0.246 & $<0.001$ & 0.001 \\
\hline
\end{tabular}

ATA, American Thyroid Association; TgAb, antithyroglobulin antibody.

4.83 years was a reasonable starting point to assess the clinical outcome, a longer follow-up is still necessary to assess the risk of late recurrences. However, most recurrences occurred within the first 5 years of follow-up after initial therapy (26). Finally, although we concluded that the variation of $\operatorname{TgAb}$ had good prognostic efficacy in disease-free patients, the prognostic efficacy was poor to predict disease persistence/recurrence. Under this circumstance, more imaging examinations, such as ${ }^{131}$ I whole body scan (WBS) and FDG PET/CT, may be needed to identify whether the disease has recurred. 


\section{CONCLUSION}

For preoperative TgAb-positive DTC patients, the variations of $\mathrm{TgAb}>-77.9 \%$ at 6 months after ${ }^{131}$ I therapy and $\mathrm{TgAb}>-88.6 \%$ at 2 years after ${ }^{131} \mathrm{I}$ therapy showed good prognostic efficacy for a tumour-free status. Their incorporation as variables in the ATA risk stratification system could more accurately predict diseasefree survival.

\section{DATA AVAILABILITY STATEMENT}

The original contributions presented in the study are included in the article/supplementary material. Further inquiries can be directed to the corresponding author.

\section{REFERENCES}

1. Haugen BR. 2015 American Thyroid Association Management Guidelines for Adult Patients With Thyroid Nodules and Differentiated Thyroid Cancer: What Is New and What Has Changed? J Cancer (2017) 123:372-81. doi: $10.1002 /$ cncr.30360

2. Haugen BR, Alexander EK, Bible KC, Doherty GM, Mandel SJ, Nikiforov YE. 2015 American Thyroid Association Management Guidelines for Adult Patients With Thyroid Nodules and Differentiated Thyroid Cancer: The American Thyroid Association Guidelines Task Force on Thyroid Nodules and Differentiated Thyroid Cancer. J Thyroid: Off J Am Thyroid Assoc (2016) 26:1-133. doi: 10.1089/thy.2015.0020

3. Chung JK, Park YJ, Kim TY, So Y, Kim SK, Park DJ, et al. Clinical Significance of Elevated Level of Serum Antithyroglobulin Antibody in Patients With Differentiated Thyroid Cancer After Thyroid Ablation. J Clin Endocrinol (2002) 57:215-21. doi: 10.1046/j.1365-2265.2002.01592.x

4. McLachlan SM, Rapoport B. Why Measure Thyroglobulin Autoantibodies Rather Than Thyroid Peroxidase Autoantibodies? J Thyroid: Off J Am Thyroid Assoc (2004) 14:510-20. doi: 10.1089/1050725041517057

5. Hjiyiannakis P, Mundy J, Harmer C. Thyroglobulin Antibodies in Differentiated Thyroid Cancer. Clin Oncol (1999) 11:240-4. doi: 10.1053/ clon.1999.9056

6. Weslley RP, Souza CMC, Gabriela FM. Follow-Up of Patients With Thyroid Cancer and Antithyroglobulin Antibodies: A Review for Clinicians. J EndocrRelat Cancer (2021) 28:R111-9. doi: 10.1530/ERC-21-0012

7. Netzel BC, Grebe SKG, Leon BGC, Castro MR, Clark PM, Hoofnagle AN, et al. Thyroglobulin (Tg) Testing Revisited: Tg Assays, Tgab Assays, and Correlation of Results With Clinical Outcomes. J J Clin Endocrinol Metab (2015) 100:E1074-83. doi: 10.1210/jc.2015-1967

8. Azmat U, Porter K, Senter L, Ringel MD, Nabhan F. Thyroglobulin Liquid Chromatography-Tandem Mass Spectrometry Has a Low Sensitivity for Detecting Structural Disease in Patients With Antithyroglobulin Antibodies. J Thyroid: Off J Am Thyroid Assoc (2017) 27:74-80. doi: 10.1089/thy.2016.0210

9. Guastapaglia L, Kasamatsu TS, Nakabashi CCD, Camacho CP, Maciel RMB, Vieira JGH, et al. The Role of a New Polyclonal Competitive Thyroglobulin Assay in the Follow-Up of Patients With Differentiated Thyroid Cancer With Structural Disease But Low Levels of Serum Thyroglobulin by Immunometric and LC-MS/MS Methods. J Endocrine (2020) 72:784-90. doi: 10.1007/s12020020-02526-8

10. Verburg FA, Luster M, Cupini C, Chiovato L, Duntas L, Elisei R. Implications of Thyroglobulin Antibody Positivity in Patients With Differentiated Thyroid Cancer: A Clinical Position Statement. J Thyroid: Off J Am Thyroid Assoc (2013) 23:1211-25. doi: 10.1089/thy.2012.0606

11. Rosario PW, Carvalho M, Mourão GF, Calsolari MR. Comparison of Antithyroglobulin Antibody Concentrations Before and After Ablation With 131I as a Predictor of Structural Disease in Differentiated Thyroid

\section{ETHICS STATEMENT}

Our research was approved by the Ethics Committee of West China Hospital of Sichuan University.

\section{AUTHOR CONTRIBUTIONS}

All the authors contributed to the study conception and design. Material preparation, data collection and analysis, writing-original draft, and writing-review and editing were performed by QL. Data collection and analysis were performed by MY. Writing-review and editing was performed by GL. And all the authors commented on previous versions of the manuscript. All authors contributed to the article and approved the submitted version.

Carcinoma Patients With Undetectable Basal Thyroglobulin and Negative Neck Ultrasonography. J Thyroid: Off J Am Thyroid Assoc (2016) 26:525-31. doi: 10.1089/thy.2015.0445

12. Kim WG, Yoon JH, Kim WB, Kim TY, Kim EY, Kim JM, et al. Change of Serum Antithyroglobulin Antibody Levels Is Useful for Prediction of Clinical Recurrence in Thyroglobulin-Negative Patients With Differentiated Thyroid Carcinoma. J Clin Endocrinol Metab (2008) 93:4683-9. doi: 10.1210/jc.20080962

13. Tian T, Kou Y, Huang R, Liu B. Prognosis of High-Risk Papillary Thyroid Cancer Patients With Pre-Ablation Stimulated $\mathrm{Tg}<1 \mathrm{Ng} / \mathrm{Ml}$. J Endocrine Pract: Off J Am Coll Endocrinol Am Assoc Clin Endocrinol (2019) 25:220-5. doi: 10.4158/EP-2018-0436

14. Dekker BL, van der Horst-Schrivers ANA, Sluiter WJ, Brouwers AH, Lentjes EGWM, Heijboer AC. Clinical Applicability of Low Levels of Thyroglobulin Autoantibodies as Cutoff Point for Thyroglobulin Autoantibody Positivity. J Thyroid: Off J Am Thyroid Assoc (2019) 29:71-8. doi: $10.1089 /$ thy.2018.0195

15. Trimboli P, Zilioli V, Imperiali M, Giovanella L. Thyroglobulin Autoantibodies Before Radioiodine Ablation Predict Differentiated Thyroid Cancer Outcome. Clin Chem Lab Med (2017) 55:1995-2001. doi: 10.1515/ cclm-2017-0033

16. Gianoukakis AG. Thyroglobulin Antibody Status and Differentiated Thyroid Cancer: What Does It Mean for Prognosis and Surveillance? Curr Opin Oncol (2015) 27:26-32. doi: 10.1097/CCO.0000000000000149

17. Morbelli S, Ferrarazzo G, Pomposelli E, Pupo F, Pesce G, Calamia I, et al. Relationship Between Circulating Anti-Thyroglobulin Antibodies (Tgab) and Tumor Metabolism in Patients With Differentiated Thyroid Cancer (DTC): Prognostic Implications. J Endocrinol Invest (2017) 40:417-24. doi: 10.1007/ s40618-016-0578-6

18. Matrone A, Latrofa F, Torregrossa L, Piaggi P, Gambale C, Faranda A, et al. Changing Trend of Thyroglobulin Antibodies in Patients With Differentiated Thyroid Cancer Treated With Total Thyroidectomy Without I-131 Ablation. Thyroid (2018) 28:871-9. doi: 10.1089/thy.2018.0080

19. Zavala LF, Barra MI, Olmos R, Tuttle M, Gonzalez H, Droppelmann N, et al. In Properly Selected Patients With Differentiated Thyroid Cancer, Antithyroglobulin Antibodies Decline After Thyroidectomy and Their Sole Presence Should Not Be an Indication for Radioiodine Ablation. Arch Endocrinol Metab (2019) 63:293-9. doi: 10.20945/2359-3997000000123

20. Seo JH, Lee SW, Ahn BC, Lee J. Recurrence Detection in Differentiated Thyroid Cancer Patients With Elevated Serum Level of Antithyroglobulin Antibody: Special Emphasis on Using 18f-FDG PET/Ct. Clin Endocrinol (2010) 72:558-63. doi: 10.1111/j.1365-2265.2009.03693.x

21. Reverter JL, Rosas-Allende I, Puig-Jove C, Zafon C, Megia A, Castells I, et al. Prognostic Significance of Thyroglobulin Antibodies in Differentiated Thyroid Cancer. J Thyroid Res (2020) 2020:6. doi: 10.1155/2020/8312628

22. Ju-Han L, Younghye K, Jung-Woo C, Young-Sik K. The Association Between Papillary Thyroid Carcinoma and Histologically Proven Hashimoto's 
Thyroiditis: A Meta-Analysis. J Eur J Endocrinol (2013) 168:343-9. doi: 10.1530/EJE-12-0903

23. Lee ZJO, Eslick GD, Edirimanne S. Investigating Antithyroglobulin Antibody as a Prognostic Marker for Differentiated Thyroid Cancer: A Meta-Analysis and Systematic Review. Thyroid (2020) 30:1601-12. doi: 10.1089/thy.2019.0368

24. Kumar A, Shah DH, Shrihari U, Dandekar SR, Vijayan U, Sharma SM. Significance of Antithyroglobulin Autoantibodies in Differentiated Thyroid Carcinoma. J Thyroid: Off J Am Thyroid Assoc (1994) 4:199-202. doi: 10.1089/ thy.1994.4.199

25. Danyang S, Xiangqian Z, Xianghui H, Chao H, Qiang J, Jian T, et al. Prognostic Value and Dynamics of Antithyroglobulin Antibodies for Differentiated Thyroid Carcinoma. J Biomarkers Med (2020) 14:1683-92. doi: 10.2217/bmm-2019-0432

26. Bates MF, Lamas MR, Randle RW, Long KL, Pitt SC, Schneider DF, et al. Back So Soon? Is Early Recurrence of Papillary Thyroid Cancer Really Just Persistent Disease? J Surg (2018) 163:118-23. doi: 10.1016/j.surg.2017.05.028
Conflict of Interest: The authors declare that the research was conducted in the absence of any commercial or financial relationships that could be construed as a potential conflict of interest.

Publisher's Note: All claims expressed in this article are solely those of the authors and do not necessarily represent those of their affiliated organizations, or those of the publisher, the editors and the reviewers. Any product that may be evaluated in this article, or claim that may be made by its manufacturer, is not guaranteed or endorsed by the publisher.

Copyright $\odot 2021 \mathrm{Liu}$, Yin and Li. This is an open-access article distributed under the terms of the Creative Commons Attribution License (CC BY). The use, distribution or reproduction in other forums is permitted, provided the original author(s) and the copyright owner(s) are credited and that the original publication in this journal is cited, in accordance with accepted academic practice. No use, distribution or reproduction is permitted which does not comply with these terms. 